\title{
Finding a Spiritual Home: A Pilot Study on the Effects of a Spirituality Retreat and Loneliness among Urban Homeless Adults
}

\author{
Joseph R. Ferrari1', Thomas Drexler², Jordan Skarr² \\ ${ }^{1}$ DePaul University, Chicago, USA \\ ${ }^{2}$ Ignatian Spirituality Project, Chicago, USA \\ Email: jferrari@depaul.edu
}

Received 25 January 2015; accepted 9 February 2015; published 12 February 2015

Copyright (C) 2015 by authors and Scientific Research Publishing Inc.

This work is licensed under the Creative Commons Attribution International License (CC BY). http://creativecommons.org/licenses/by/4.0/

(c) (7) Open Access

\begin{abstract}
Social agencies and services exist in urban settings for the physical needs of homeless citizens. However, there exist few if any programs that feed the spiritual needs of the homeless. In the present study, 35 women and 23 men (55.9\% African-American) competed short, reliable and valid self-report measures on their levels of loneliness and addiction before and then again 6-month post a weekend religious retreat. Results indicate that over time, participants on the retreat reported significant decreases in loneliness. Women reported significantly higher rates of loneliness at baseline and again at 6-month follow-up, compared to men. It seems offering a group-based spiritual retreat may impact the lives of homeless.
\end{abstract}

Keywords

Loneliness, Addiction, Homelessness, Retreats, Spirituality

\section{Introduction}

It has been reported that on any given night, over 600,000 people were homeless in America (US Department of Housing \& Urban Development, 2013). Government statistics report that about two-thirds were homeless adults, and many have physical disabilities. Almost 100,000 people were chronically homeless, such that these persons were homeless for at least a year, or experienced at least four episodes of homelessness within the past three years. Almost two-thirds of homeless people may be found in emergency shelter or transitional housing sites, while the remainder lived in unsheltered locations such as streets or abandoned buildings. Social agencies and non-profit programs often focus on the physical needs of the homeless (e.g., food and safe living spaces), yet 
few if any programs offer consistent initiatives that "feed the spiritual need". Although many 12-step programs include a level of spirituality (e.g., appealing to a "higher power") focusing on religious practices directly (prayer and spiritual reflection) are prohibited.

Gravell (2013) provided a detailed study of the spiritual needs of 75 homeless individuals in London, England. Results from qualitative interviews revealed that homeless people, like most other individuals, feel that religious belief and spiritual practice have benefits in their personal life. Participants noted that spiritual programs, if available, would provide them an improved ability to cope with losses in the past, a better perspective of the present, and forming a meaningful future with oneself and others (Gravell). However, despite the claimed benefits, participants noted they were rarely asked about their spiritual needs regardless of social service agency providers. That is, both religious or secular service agencies which offered them food and housing seemed never to address their important personal religious or spiritual desires.

In short, meeting basic material needs like food and safe, sober shelter, of course, is essential to survival for everyone, especially the homeless. In this brief exploratory study we examined how a weekend religious retreat program impacted on the self-reported levels of loneliness and addiction usage among a small sample of adult homeless women and men. Because there seems to be no published research in the literature on this specific topic, we did not enter with any strong predictions other than the fact that we expected loneliness levels to change over time as the spiritual needs of participants were met.

\subsection{Negative Consequences of Loneliness}

Recent studies demonstrated that loneliness is "bad for your health" (Segrin \& Domschke, 2011). Physically, social isolation was linked to heart disease, smoking addiction, obesity (Norman, Cacioppo, Morris, Malarkey, Berntson, \& DeVries, 2011), nausea, headaches, eating disturbances (Pritchard \& Yalch, 2009), sleep disturbances (Cacioppo et al., 2002), and poorer immune systems effectiveness (Kiecolt-Glaser, Ricker, George, Messick, Speicher, Garner, \& Glaser, 1984). Loneliness also has psychological consequences related to depression and other mental illnesses (Cacioppo, Hawkley, Berntson, Ernst, Gibbs, Stickgold, \& Hobson, 2002; Rokach, 2011). Isolation breeds boredom, stress, and frustration which may place a person at risks for substance use (Garcia-Rea \& LePage, 2008). Taken together, the negative effects of loneliness both physically and mentally seems to have short and long term devastating effects on the body and "soul".

\subsection{Loneliness and Homelessness}

Those individuals that are homeless suffer from reduced social support networks (Lam \& Rosenheck, 1999). Isolation from being homeless may add stressor, leaving the person faced with both long term and short term physical and emotional consequences. These problems also may aggravate preexisting conditions, such as major depression, bipolar disorder, borderline personality disorder, and schizophrenia-particularly among women (Douglas, Jimenez, Lin, \& Frisman, 2008; Lowe \& Gibson, 2011). Even when treated, medical conditions may make it difficult for positive life changes toward independent living, producing a perpetual cycle of homelessness (Garcia-Rea \& LePage, 2008). By addressing loneliness and fostering social support networks for the homeless, community organizations may create scaffolding that provides a supportive environment for persons trying to get off the streets and live independent lives. Unfortunately, many government and even non-profit social agency programs focus on large scale outreach initiatives that do not have the social capital or resources to focus on emotional let alone spiritual issues for the homeless. Because one might argue that government agencies should remain secular and not offer religious programs, there may be a void in initiatives that fill this spiritual gap in the lives of homeless men and women.

Some of the most effective homeless interventions programs center on a model of individualized case management. These programs create a personalized roadmap back to independence for the individual based on the person's own goals (Furlong, Leddy, Ferguson, \& Heart, 2009). Individualized care programs were strong predictors of independent living, more successful control of psychiatric symptoms, and better ratings of quality of life, as well as gains in employment and greater family satisfaction (Furlong et al.). In one study of individualized case management programs for homeless persons who suffered from chronic illnesses (Davis, Tamayo, \& Fernandez, 2012), participants stated that the "caring personal relationships with the case managers were key to the program" and firmly believed that "their health improved through both the interpersonal and practical aspects of the case management". 
Taken together, positive and substantial benefits results may result from fostering social support networks in the recovering process among homeless adults. Such social interventions gave homeless clients support not found on the street. This support gives them the strength and connections to make changes for themselves (Furlong et al., 2009; Davis et al., 2012; Morse, Calsyn, Allen, Tempelhoff, \& Smith, 1992). By allowing the clients to create their goals, case managers empower clients to make changes for themselves, providing help only when needed (Furlong et al.).

Although individualized case management programs may be effective, they may not be financially feasible. Funding and staffing are insufficient to meet the needs of a growing homeless population. Consequently, exploring alternative methods to foster feelings of connection and social support through membership in organizations and social groups seems warrented. Persons in groups or organizations report larger social networks, more contact with others in their social network, and significant coping mechanisms against psychological distress compared to persons who do not claim membership (Masi, Chen, Hawkley, \& Cacioppo, 2011; Paloutzian \& Park, 2013). Being a member also opens the door to accessing additional employment support and resources (Ellison \& George, 1994).

While improvements were seen from general membership in secular organizations, Acevedo, Ellison, and Xu (2014) suggest that there may be a relationship between religious membership affiliation and enhanced outcomes for personal adjustment than comparable membership in secular organizations. On average, individuals with religious membership showed larger emotional support systems, more frequent contact with other members, and access to significantly more types of social support than those reported by participants in secular organizations. Other studies found that formal religious membership may help buffer against the negative health issues associated with "cumulative stress” from multiple sources such as work stress and/or experiencing racism (Copeland-Linder, 2006; Ellison \& George, 1994). With stress-buffering abilities associated with religious membership, the feeling of belonging decreases the intensity of stress and, in turn, decreases the negative physical and emotional effects stress brings with it that may arise from loneliness (Acevedo et al.; Copeland-Linder).

It is possible that religious membership significantly buffers against stress and loneliness because of the power of group prayer. Prayer has provided individuals with multiple positive resources, such as an “other” to whom one can express and vent anger and joy, positive reflected appraisals, buffering against threatening situations, and an emotion management model (Copeland-Linder, 2006; Sharp, 2010). Prayer practices provide religious members similar minded peers to talk to at any time and who care about their experiences while listening to their experiences (Piraino, Krema, Williams, \& Ferrari, 2014). Because of their homeless status, the homeless often become invisible members of society (Mallett, 2004). Prayer gives the homeless, as well as anyone who turns upward for answers, their voice back. Praying among the homeless has been found to be a positive experience for both the homeless clients and groups facilitators (Piraino et al.). In the present study, we explored the impact of prayer through a religious retreat on the feeling of isolation and loneliness among men and women homeless individuals.

In 1998, the Ignatian Spirituality Project (ISP), an initiative designed to build hope and offer spiritual fulfillment within homeless populations, was developed (Creed, 2007). The organization's goals include "conducting retreats and spiritual programming for those experiencing homelessness; developing a national network to sustain those efforts; reflecting on systemic issues which may be addressed by this network.” (Ignatian Spirituality Project, n.d.) ISP hosts weekend long (Saturday morning to Sunday afternoon) spiritual retreats in several US urban cities and each retreat covers themes like recovery, fear and trust, healing of memories, and includes time in nature and opportunities for group prayer. The retreat fosters reflection and introspection, transformation, and reconciliation among homeless participants (Ignatian Spitiruality Project, n.d.). All meals are provided during the weekend. These events invite participants to speak up, to share one-on-one with others, to work together, and to experience the gifts of community. An unpublished manuscript by Rowell, Creed, Skarr, and McGraw (2012) found there was satisfaction with the program on the actual retreat. However, there was no assessment on how this experience might impact on the feelings of loneliness among participants, and how over time there might be some lasting impact of the retreat experience.

\section{Method}

\subsection{Participants}

Participants were 59 self-identifying homeless adults (35 female, 23 male) recruited from homeless shelters, 
halfway houses, or housing program sites. The majority of participants (55.9\%) self-identified as African-American. All participants were over the age of 21 years old, although there was no data collected on their specific age. Most participants (86.8\%) reported they were living in a shelter or halfway house and were unemployed for a period of at least one year (84.5\%). Most participants also were involved in a 12-step recovery program (68.7\%), attended AA meetings regularly (76.8\%), and had an AA sponsor (51\%).

\subsection{Psychometric Measures}

After signing a consent form, participants completed demographic questions, including gender, ethnicity, highest grade/degree completed, current employment and housing status, and current recovery activity. Participants also completed two self-reported instruments.

Revised UCLA Loneliness Scale. Loneliness was measured using the Revised, Brief University of CaliforniaLos Angeles (UCLA) Loneliness scale (Hughes, Waite, Hawkley, \& Cacioppo, 2004). This measure is a threequestion questionnaire which asks participants how often they feel they lack companionship, how often they feel left out, and how often they feel isolated from others. Respondents use a 3-point Likert scale $(1=$ hardly ever, 2 = some of the time, $3=$ often). Lower scores on this scale indicate lower levels of loneliness. This brief scale has good reliability and validity, similar to that of the original scale (Hughes et al.); with the current sample, coefficient alpha was 0.81 at baseline and at the six-month follow-up of 0.81 .

CAGE questionnaire. The CAGE (Ewing, 1984) questionnaire is a 4-item "yes/no" survey asking respondents if they 1) $\mathrm{C}=$ have ever felt the need to cut down their drinking, 2) $\mathrm{A}=$ felt annoyed by criticism of their drinking, 3) G = had guilty feelings about drinking, and 4) E = had taken a morning "eye opener" alcoholic drink to help wake up. Answering "yes" to two or more questions indicated signs of possible alcohol dependency. This questionnaire was meant as a screening instrument rather than a diagnostic tool, but its efficiency and effectiveness lent itself well to this particular context as a quick indicator. With the current sample, coefficient alpha for this brief scale was 0.85 at baseline and 0.90 at the six-month follow-up.

\subsection{Procedure}

The ISP retreat process. Participants were recruited by ISP volunteers from homeless shelters across each of five major urban cities (Chicago, St. Louis, Cleveland, Denver, and Washington DC) on a Saturday morning and were explained the nature of the retreat which would include food and shelter for the weekend, as well as in various religious-based activities, such as art projects, prayer, and small group discussions. The focus for these retreats were being together and building trust. After arriving at 9:00 am at the retreat center in that city, a 60minute "welcome" ice breaker session was held where participants were introduced to one another. Retreat ground rules were stated and the group said an opening prayer. Then, participants engaged in a trust exercise and went to lunch. After small groups, ISP held a two part topic session, with opportunities to spend time in nature, journal, and discuss the healing presence of God in one's life. Next, participants ate dinner and participated in a film or art activity for the evening. At about 8:30 pm, participants held evening prayer and could write a letter to God before going to bed.

Before the retreat resumed on Sunday, participants were invited to an optional early morning reflection. After breakfast, participants were invited to engage in a morning prayer, followed by a partnered discussion. Participants then were given a break, to pack or finish up their letter to God. The group then discussed "where to go from here", and participated in small group conversations. At 11:30 am, participants said a closing prayer and ended the retreat. ISP volunteers then escorted participants back to their respective homeless shelters.

Data collection. Before completing any measures, retreat attendees were informed of this study and asked to sign and date a consent form, in agreement with ethical approved guidelines. Participants filled out the demographic items and both self-report measures prior to taking part in the retreat on Saturday. At a 6-month followup to the retreat, attendees were found by ISP volunteers and asked to complete both survey measures. All participants were able to read and understand the seven psychometric items, and it took participants less than 10 minutes at each wave to complete all information. The present study focused only on persons who completed both baseline and the 6-month follow-up, which represented about $15 \%$ of the sample.

\section{Results}

Preliminary analysis indicated no significant difference on loneliness or CAGE scores across the five city sites 
$(p>0.10)$. Subsequently, a repeated measure ANOVA was conducted for the effects of change over time on the two waves of data for CAGE and loneliness scale scores. There was a statistically significant overall effect over time, $F(2,57)=3.13, p=0.05$; Wilk's $\Lambda=0.90$, partial $\eta^{2}=0.10$. Uni-variate tests show no significant difference on $C A G E$ scores, $F(1,58)=0.56, p=0.15$; indicating no statistically significant change in drug abuse between Time $1(M=2.71, S D=1.52)$ and Time $2(M=2.59, S D=1.64)$. There were, however, significant effects on UCLA Loneliness Scale scores, $F(1,58)=4.73, p=0.03$, partial $\eta^{2}=0.08$, indicating a significant decrease in loneliness between Time $1(M=6.00, S D=1.74)$ and Time $2(M=5.55, S D=1.91)$.

Next, we adding race and gender identity to the model and conducted a 2 (African-American vs. other) by 2 (women vs. men) ANOVA on CAGE and loneliness scores. There was no significant effect of ethnicity, or the interaction between ethnicity and gender. There was, however, a significant effect of gender when looking at between subjects multivariate tests, $F(2,48)=3.29, p=0.046$, partial $\eta^{2}=0.12$, indicating that women had higher rates of loneliness at Time $1(M=6.29, S D=1.53)$ and Time $2(M=6.00, S D=1.75)$, than men did at Time $1(M=5.57, S D=1.97)$ and Time $2(M=4.87, S D=1.98)$. Within subject tests showed no significant differences on CAGE or loneliness scores.

\section{Discussion}

These results of the present highly exploratory study may provide some evidence for an effect of religious retreats, like those used by ISP, on feelings of loneliness for women and men. Over time, participants of such retreats report feeling less lonely, although women maintain a higher rate of isolation than men. Douglas et al. (2008) found the spiritual needs of loneliness in women may be impacted by interventions, and the present study suggests that religious retreats may be such a mechanism. The reduction in isolation seems to occur regardless of one's ethnic identity. These results are consistent also with Gravell's (2013) study with homeless adults in London, in that there is a need for attending to the spiritual needs of those experiencing homelessness. Moreover, the present study shows that such programs impact on feeling isolated and lonely.

Limitations and future directions. Of course, this brief pilot study has several limitations that impact on our conclusions. For example, future research should aim at looking at personal adjustment outcomes related to loneliness (such as self-esteem, stress management, and coping strategies). Our sample was small (impacting power effects) and we did not have a control group of homeless adults who did not participate in the retreat. Future studies need larger sample sizes addressing these issues, and including manipulation checks. Furthermore, it would be interesting to examine the effect of repeated retreat involvement with homeless adults' feelings on varied psychological factors. While the present study found that a spiritual retreat experience had significant impact over time, the lasting effects of such programs needs further study. We did not directly explore which components of the retreat impacted (or failed to impact) on loneliness and recovery among participants.

Nevertheless, providing spiritual services that may decrease loneliness feelings among homeless men and women suggest that such programs might benefit society. We believe that as a society we need to not continue to focus solely on the material needs of homeless people although these needs are clearly important. Instead, we should begin to look at the experiences of homelessness from a more holistic standpoint and provide services that allow homeless persons to develop personal meaning and insight from life. Our study is very limited, but it does raise important program issues for future investigation. Secular government agencies may offer momentary relief from the hopelessness and despair experienced that often accompanies homelessness (Piraino et al., 2014), much like a "soup kitchen hot meal" provides momentary relief from hunger. Still, we propose that non-profit agencies (like ISP) need to expand the availability spiritual programming to provide much needed hope.

\section{Acknowledgements}

We are grateful to Crystal Steltenpohl and Danielle Vaclavik for data entry, analysis and early drafts of the final paper. Gratitude is expressed to the women and men from Chicago, Cleveland, Denver, St. Louis, and Washington DC, who volunteered to participate in this project. Funding for this project was provided by the Ignatian Spirituality Project, Chicago, IL.

\section{References}

Acevedo, G. A., Ellison, C. G., \& Xu, X. (2014). Is It Really Religion? Comparing the Main and Stress-Buffering Effects of Religious and Secular Civic Engagement on Psychological Distress. Society and Mental Health, 4, 1-18. http://dx.doi.org/10.1177/2156869313520558 
Cacioppo, J. T., Hawkley, L. C., Berntson, G. G., Ernst, J. M., Gibbs, A. C., Stickgold, R., \& Hobson, J. A. (2002). Do Lonely Days Invade the Nights? Potential Social Modulation of Sleep Efficiency. Psychological Science, 13, 384-387. http://dx.doi.org/10.1111/j.0956-7976.2002.00469.x

Cacioppo, J. T., Hawkley, L. C., Crawford, L. E., Ernst, J. M., Burleson, M. H., Kowalewski, R. B., Berntson, G. G. et al. (2002). Loneliness and Health: Potential Mechanisms. Psychosomatic Medicine, 64, 407-417. http://dx.doi.org/10.1097/00006842-200205000-00005

Copeland-Linder, N. (2006). Stress among Black Women in a South African Township: The Protective Role of Religion. Journal of Community Psychology, 34, 577-599. http://dx.doi.org/10.1002/jcop.20116

Creed, W. E. (2007). Studies in the Spirituality of Jesuits. Chicago, IL: Seminar on Jesuit Spirituality.

Davis, E., Tamayo, A., \& Fernandez, A. (2012). Because Somebody Cared about Me. That's How It Changed Things: Homeless, Chronically Ill Patients’ Perspectives on Case Management. PLOS ONE, 7, 1-7. http://dx.doi.org/10.1371/journal.pone.0045980

Douglas, A. N., Jimenez, S., Lin, H. J., \& Frisman, L. K. (2008). Ethnic Differences in the Effects of Spiritual Well-Being on Long-Term Psychological and Behavioral Outcomes within a Sample of Homeless Women. Cultural Diversity and Ethnic Minority Psychology, 14, 344-352. http://dx.doi.org/10.1037/1099-9809.14.4.344

Ellison, C., \& George, L. (1994). Religious Involvement, Social Ties and Social Support in a Southeastern Community. Journal for the Scientific Study of Religion, 33, 46-61. http://dx.doi.org/10.2307/1386636

Furlong, M., Leddy, J., Ferguson, J., \& Heart, K. (2009). Assertive Community Treatment and Recovery at Thresholds. American Journal of Psychiatric Rehabilitation, 12, 108-123. http://dx.doi.org/10.1080/15487760902812998

Garcia-Rea, E., \& LePage, J. P. (2008). Reliability and Validity of World Health Organization Quality of Life-100 in Homeless Substance-Dependent Veteran Population. Journal of Rehabilitation Research \& Development, 45, 619-626. http://dx.doi.org/10.1682/JRRD.2007.03.0048

Gravell, C. (2013). Lost and Found: Faith and Spirituality in the Lives of Homeless People. London: Lemos \& Crane Publishers.

Hall, D. (2006). Religious Attendance: More Cost-Effective Than Lipitor? Journal of the American Board of Family Medicine, 19, 130-139. http://dx.doi.org/10.3122/jabfm.19.2.103

Hughes, M. E., Waite, L. J., Hawkley, L. C., \& Cacioppo, J. T. (2004). A Short Scale for Measuring Loneliness in Large Surveys: Results from Two Population-Based Studies. Research on Aging, 26, 655-672.

Ignatian Spirituality Project (n.d.). History and Mission. http://www.ignatianspiritualityproject.org/?page_id=14

Ignatian Spitiruality Project (n.d.). Our Program. http://www.ignatianspiritualityproject.org/?page_id=19

Kiecolt-Glaser, J. K., Ricker, D., George, J., Messick, G., Speicher, C. E., Garner, W., \& Glaser, R. (1984). Urinary Cortisol Levels, Cellular Immunocompetency, and Loneliness in Psychiatric Inpatients. Psychosomatic Medicine, 46, 15-23. http://dx.doi.org/10.1097/00006842-198401000-00004

Lam, J. A., \& Rosenheck, R. (1999). Street Outreach for Homeless Persons with Serious Mental Illness: Is It Effective? Medical Care, 37, 894-907. http://dx.doi.org/10.1097/00005650-199909000-00006

Lowe, J., \& Gibson, S. (2011). Reflections of a Homeless Population's Lived Experience with Substance Abuse. Journal of Community Health Nursing, 28, 92-104. http://dx.doi.org/10.1080/07370016.2011.564066

Mallett, S. (2004). Giving Voice? Or Hearing Voices? A Personal Reflection on the Politics of Speaking and Listening in the Homelessness Sector. Parity, 17, 4-5.

Masi, C. M., Chen, H. Y., Hawkley, L. C., \& Cacioppo, J. T. (2011). A Meta-Analysis of Interventions to Reduce Loneliness. Personality and Social Psychology Review, 15, 219-266. http://dx.doi.org/10.1177/1088868310377394

Morse, G. A., Calsyn, R. J., Allen, G., Tempelhoff, B., \& Smith, R. (1992). Experimental Comparison of the Effects of Three Treatment Programs for Homeless Mentally Ill People. Hospital and Community Psychiatry, 43, 1005-1010.

Norman, G. J., Cacioppo, J. T., Morris, J. S., Malarkey, W. B., Berntson, G. G., \& DeVries, A. C. (2011). Oxytocin Increases Autonomic Cardiac Control: Moderation by Loneliness. Biological Psychology, 86, 174-180. http://dx.doi.org/10.1016/j.biopsycho.2010.11.006

Paloutzian, R. F., \& Park, C. L. (2013). Recent Progress and Core Issues in the Science of the Psychology of Religion and Spirituality. In R. F. Paloutzian, \& C. L. Park, Handbook of the Psychology of Religion and Spirituality (2nd ed., pp. 3-22). New York: Guilford Press.

Piraino, A., Krema, G., Williams, S. M., \& Ferrari, J. R. (2014). “Hour of HOPE”: A Spiritual Prayer Program for Homeless Adults. Universal Psychology, 2, 1-4.

Pritchard, M. E., \& Yalch, K. L. (2009). Relationships among Loneliness, Interpersonal Dependency, and Disordered Eating in Young Adults. Personality and Individual Differences, 46, 341-346. http://dx.doi.org/10.1016/j.paid.2008.10.027 
Rokach, A. (2011). From Loneliness to Belonging: A Review. Psychology Journal, 8, 70-81.

Rowell, N., Creed, B., Skarr, J., \& McGraw, D. (2012). The ISP Outcome Survey: Moving from a Faith Statement to Statistical Evidence: A Two-Year Study on the Change Associated with Attending an ISP Retreat. Chicago, IL: Ignatian Spirituality Project.

Segrin, C., \& Domschke, T. (2011). Social Support, Loneliness, Recuperative Processes, and Their Direct and Indirect Effects on Health. Health Communication, 26, 221-232. http://dx.doi.org/10.1080/10410236.2010.546771

Sharp, S. (2010). How Does Prayer Help Manage Emotions? Social Psychology Quarterly, 73, 417-437. http://dx.doi.org/10.1177/0190272510389129

U.S. Department of Housing \& Urban Development (2013). The 2013 Annual Homeless Assessment Report (AHAR) to Congress. Washington DC: US Department of Housing and Urban Development. 
Scientific Research Publishing (SCIRP) is one of the largest Open Access journal publishers. It is currently publishing more than 200 open access, online, peer-reviewed journals covering a wide range of academic disciplines. SCIRP serves the worldwide academic communities and contributes to the progress and application of science with its publication.

Other selected journals from SCIRP are listed as below. Submit your manuscript to us via either submit@scirp.org or Online Submission Portal.
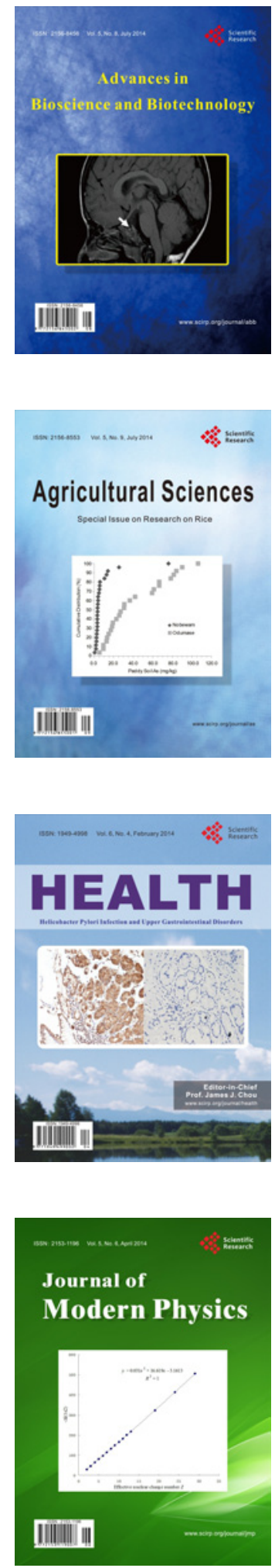
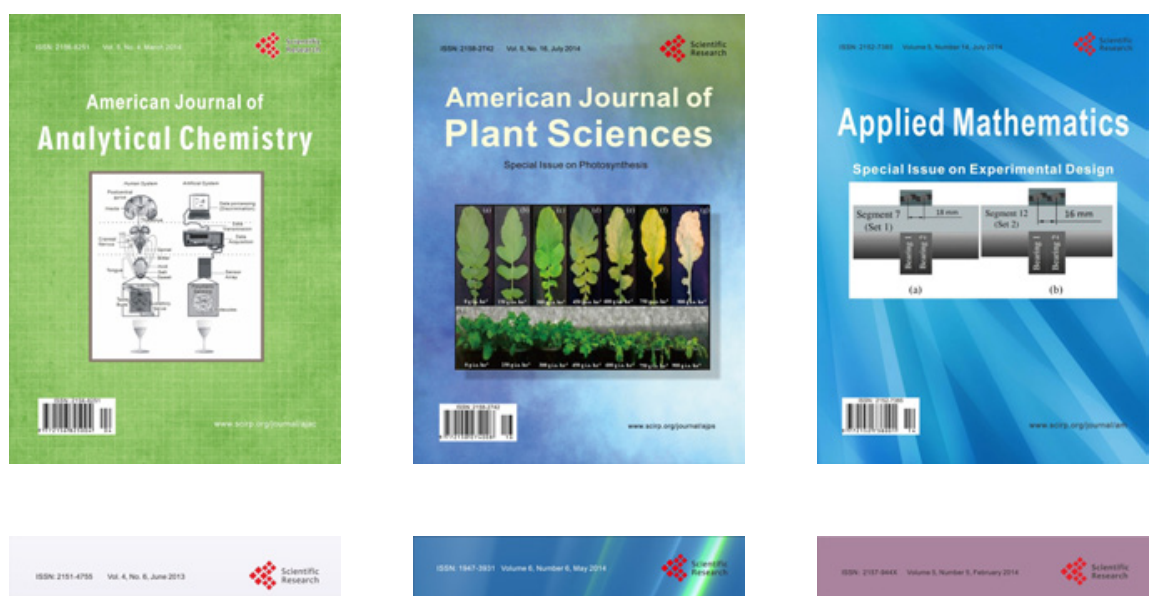

Creative Education
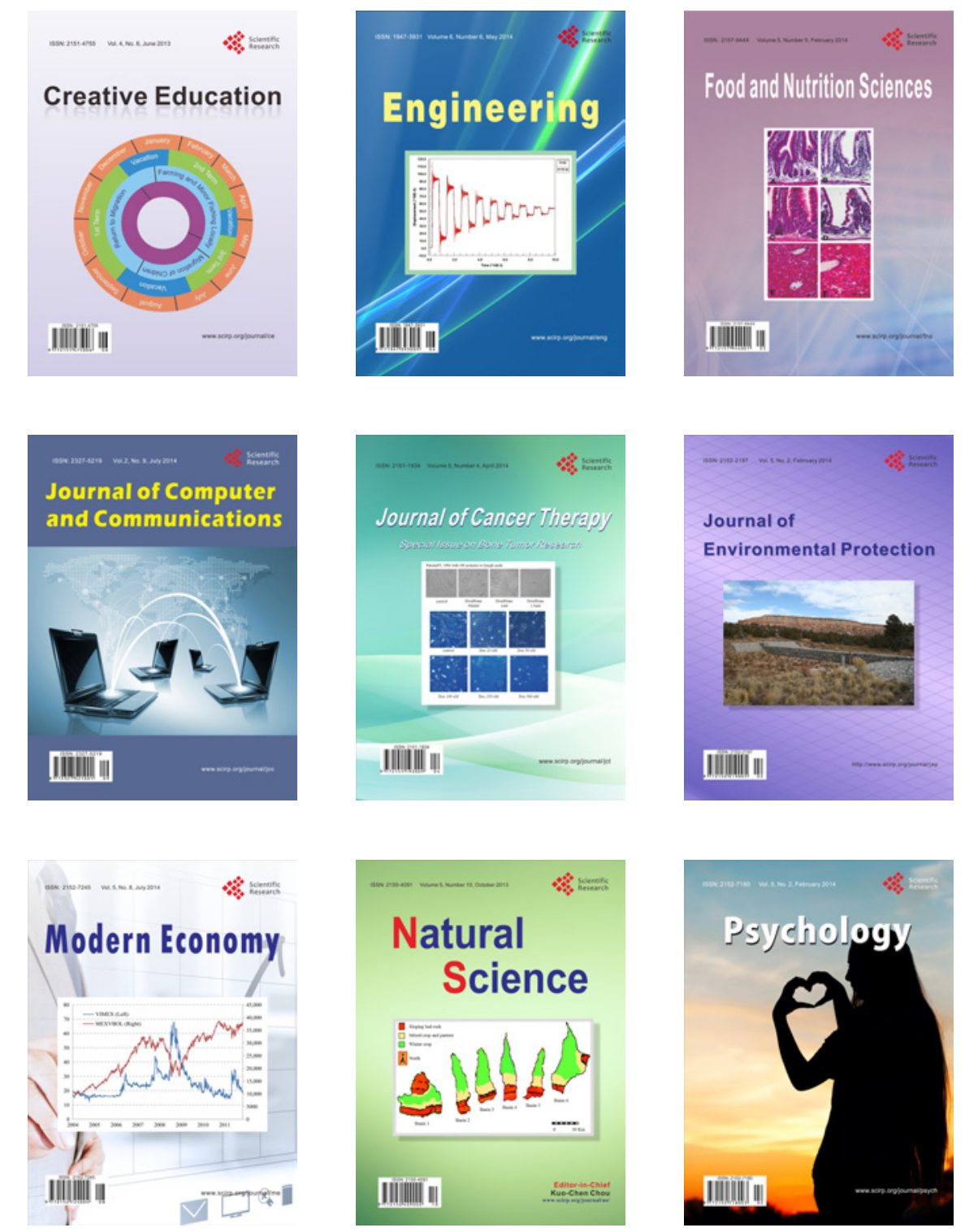